Terr. Atmos. Ocean. Sci., Vol. 18, No. 1, 19-30, March 2007

\title{
Crustal Resistivity Anomalies Beneath Central Taiwan Imaged by a Broadband Magnetotelluric Transect
}

\author{
Chow-Son Chen ${ }^{1, *}$, Chien-Chih Chen ${ }^{1}$, Chih-Wen Chiang ${ }^{1}$, Hun-Lun Shu ${ }^{1}$, \\ Wei-Hsuan Chiu ${ }^{1}$, Martyn J. Unsworth ${ }^{2}$, and Edward Bertrand ${ }^{2}$
}

(Manuscript received 15 June 2006, in final form 30 October 2006)

\begin{abstract}
The Taiwan orogeny is young and presently very active. To improve understanding of the tectonics of Taiwan, especially the present of fluid of interconnected fluids such as water and partial melts in the Earth's crust, a transect across the central island of Taiwan by using broadband magnetotelluric (MT) soundings was made from 1995 - 2006. More than 80 MT stations were surveyed around this transect and a profile almost perpendicular to the regional strike of Taiwan was obtained. A 2-D constrained inversion was implemented and included static shift, topography and the ocean effect. This resistivity model is characterized by three main conductive anomalies located beneath the Coastal Plains, Central Range and Longitudinal Valley. Correlation of the conductors to the seismicity, the heat flow and surface geology of Taiwan suggest that the Coastal Plain conductor represents fluids, the Central Range conductor reflects both fluids and the effect of enhanced temperature, and the Longitudinal Valley conductor depicts the suture zone of the plates' boundary, respectively. These low resistivity zones could represent zones of reduced viscosity that may control the deformation of this active orogen. The GPS observations of a general motion in Taiwan area support this tectonic implication.
\end{abstract}

(Key words: Magnetotelluric method, Crustal electrical conductor, Crustal fluid, Taiwan orogeny, Constrained inversion)

\footnotetext{
${ }^{1}$ Institute of Geophysics, National Central University, Chung-Li, Taiwan, ROC

2 Department of Physics, University of Alberta, Edmonton, Canada

* Corresponding author address: Prof. Chow-Son Chen, Institute of Geophysics, National Central University, Chung-Li, Taiwan, ROC; E-mail: chusen@earth.ncu.edu.tw
} 


\section{INTRODUCTION}

The Taiwan orogen was created by the collision between the Eurasian Plate and the Philippine Sea Plate (Fig. 1a) that began about $3 \mathrm{Ma}$ (Teng 1990). The overall plate configuration in the vicinity of Taiwan is defined by seismicity (Wu et al. 1997). While the Philippine Sea plate is subducting northwestward from the Ryukyu Trench in the northeast of Taiwan, the Eurasian plate is subducting beneath the Philippine Sea plate along the Manila Trench in the south of Taiwan. The seismicity and the geodetically measured deformation (Yu et al. 1990) all indicate that the ongoing tectonics in and around Taiwan is very active. This rapid arccontinental collision is responsible for the dominant geologic variations that occur east-west across the island, with rocks generally becoming older, more metamorphosed, and more intensely deformed to the east. The geologic provinces of Taiwan comprise, from west to east, are as follows (Fig. 1b): (1) the Coastal Plains (CP), (2) the Western Foothills (WF), (3) the Hsueshan Range (HR), (4) the western Central Range (CR), (5) the eastern Central Range (CR), (6) the Longitudinal Valley (LV), and (7) the Coastal Range (COR).

The crustal and upper-mantle structure of Taiwan has been investigated by a number of seismic studies (Rau and Wu 1995; Wu et al. 1997). However little is known about the electrical resistivity structure. Electric resistivity is an important intrinsic property of the Earth, that is sensitive to the presence of small amounts of fluid, melt or electrically conductive minerals. These are volumetrically minor constituents of the Earth's crust and mantle but can have a significant effect on the rheology and control the tectonics. Electromagnetic imaging of subsurface resistivity structure has made important contributions in the study of active tectonics. The tectonic setting of Japan is quite similar to Taiwan and was imaged by a number of magnetotelluric studies (Mitsuhata et al. 2001; Ogawa et al. 2001; Ogawa and Honkura 2004). This work revealed that fluids are widely distributed in the mid-crust, and related to seismicity and surface deformation. In Southern Tibet, the collision between the Eurasian Plate and the India Plate, aqueous fluids and partial melts were detected in the mid-crust using MT imaging (Li et al. 2003; Unsworth et al. 2005).

In this paper broadband magnetotelluric (MT) data collected across central Taiwan are described. The purpose of this MT study is to improve our understanding of the tectonics of Taiwan, especially the presence of fluids that may delineate zones of active deformation.

\section{MAGNETOTELLURIC DATA COLLECTED IN TAIWAN}

Broadband magnetotelluric data were collected on an east-west profile in Central Taiwan (Fig. 1b) with frequencies in the band $300-0.0005 \mathrm{~Hz}$. The transect extended from the Coastal Plains, across the Central Ranges and terminated at the east coast. The location of the profile was chosen to determine whether there are differences in electrical conductivity within the Taiwan mountain range. Broadband MT data were collected at more than 80 locations spaced 1 - $10 \mathrm{~km}$ apart. High levels of cultural noise were present at a number of sites, and thus high quality MT data was not collected at all sites. MT data of usable quality were projected onto the profile trace. Only a few stations were collected in the Central Range because of the rugged topography. However, numerical modeling showed that MT soundings on both sides of the $\mathrm{CR}$ could detect the presence of a conductive layer to depths of $25 \mathrm{~km}$ beneath this region. 
(a)

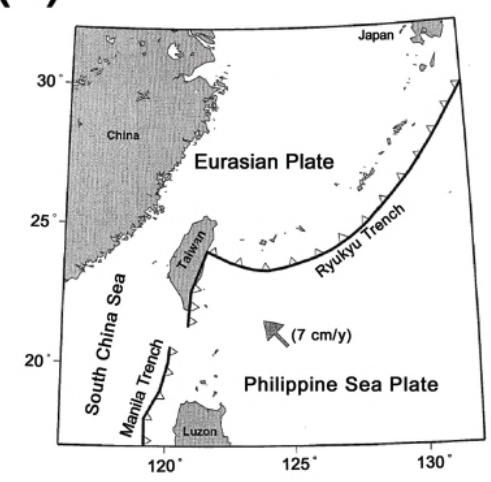

(b)

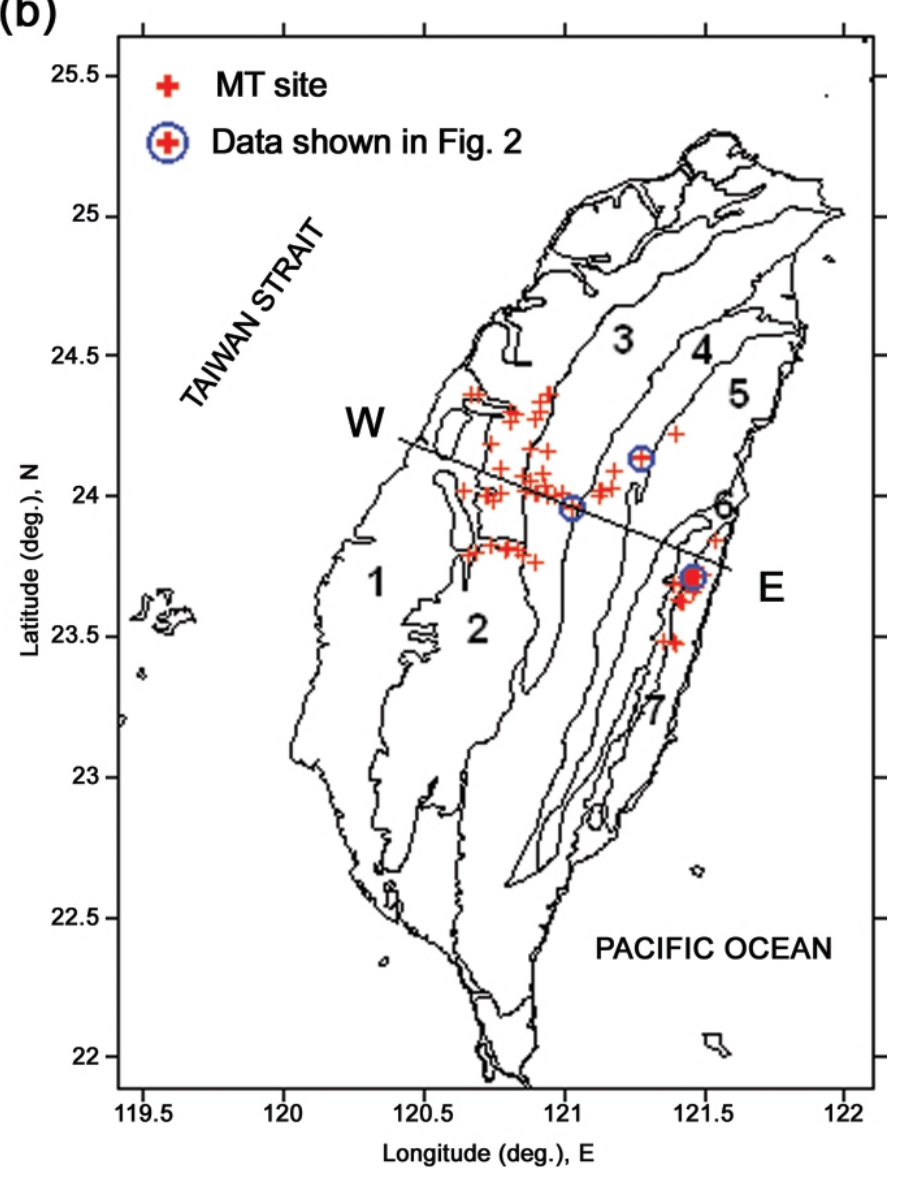

Fig. 1. (a) General tectonics of Taiwan (After Lin 2000). Bold lines indicate the major convergent boundary between the Philippine Sea and Eurasian Plates. Triangles marked along either side of the boundary represent the direction of subduction. The relative plate motion vector $\left(7 \mathrm{~cm} \mathrm{yr}^{-1}\right)$ of the Philippine Sea Plate with respect to the Eurasian Plate is shown as an arrow. (b) Location map of the MT survey in Central Taiwan. The location of eastwest profile and simplified geological region of Taiwan (Ho 1988) are also shown. 1 = Coastal Plain; 2 = Western Foothills; 3 = Hsuehshan Range; $4=$ Western Central Range; 5 = Eastern Central Range; $6=$ Longitudinal Valley; and $7=$ Coastal Range. 
The data were collected using a combination of broadband MT instruments produced by Phoenix Geophysics. Prior to 2000 Phoenix V5 instruments were used. After 2000 the Phoenix V5 - 2000 system was used. Where possible five-components (three magnetic and two electric) were measured with an MTU5 instrument. At other stations only the electric fields were recorded with 2E instruments. Data recording on each instrument was synchronized using timing signals from GPS satellites. At the $2 \mathrm{E}$ stations, impedances were calculated using magnetic fields recorded at neighboring 5-channel sites. Clean time-series data were used for remote reference processing (Gamble et al. 1979). Remote reference processing improved the data quality at periods longer than $1 \mathrm{~s}$. The MT dataset used in this study combined previous surveys (Chen and Chen 1998, 2000, 2002) with more recent data collected as part of the international TAIGER-MT project. In total, more than 80 MT soundings were collected in central Taiwan.

Three typical MT soundings are shown in Fig. 2. The apparent resistivity curve marked transverse electric (TE) was computed from north-south electric currents, while the transverse magnetic (TM) curve was computed from east-west electric currents. The differences between the TE and TM modes indicate that these data are multidimensional (not 1-D), since a 1-D earth produces MT responses that are identical at all measurement azimuths. The observed MT data are shown in the pseudo-sections of Figs. $3 \mathrm{~b}$ and c. The apparent resistivity in the Central Ranges (distances $70-100 \mathrm{~km}$ ) exhibit relatively high values of apparent resistivity and low phases in TM mode, which implies that the structure is resistive. However, the phases in this region increase and the apparent resistivities decrease in TE mode, indicating a conductor at depth.

The major geological units in Taiwan are aligned in the direction $\mathrm{N} 20^{\circ} \mathrm{E}$ (Ho 1988). Seismic wave tomography (Rau and $\mathrm{Wu} 1995$ ) also reveals that subsurface structures vary more rapidly in the east-west direction than in the north-south direction. Thus a two-dimensional modeling approach was used for the MT data. To investigate the effect of strike direction on the inversions, two possible geoelectric strike directions were considered throughout the following analysis; one $\mathrm{N}-\mathrm{S}$ and the other $\mathrm{N} 20^{\circ} \mathrm{E}$, reflecting the geologic trend of Taiwan. In the inversion models, we look for conductivity features that are independent of the choice of strike direction.

\section{CONSTRAINED INVERSION OF THE MAGNETOTELLURIC DATA}

The widely used 2-D magnetotelluric inversion scheme of Rodi and Mackie (2001) was used to invert the apparent resistivity and phase data. The ocean structure and topography were included in the inversion. The inversions began from a $100 \mathrm{ohm}-\mathrm{m}$ starting model and static shifts were estimated by the inversion.

MT data of limited frequency bandwidth may not be able to detect the bottom of a conductive layer. This leads to a problem if the inverse algorithm uses a maximum smoothness constraint to overcome non-uniqueness, because the algorithm will simply smear the conductor to infinite depth and give a layer conductance that is too large. To solve this problem, a constrained inversion can be used ( $\mathrm{Li}$ et al. 2003). In this approach, the model is forced to be 
Chen et al.

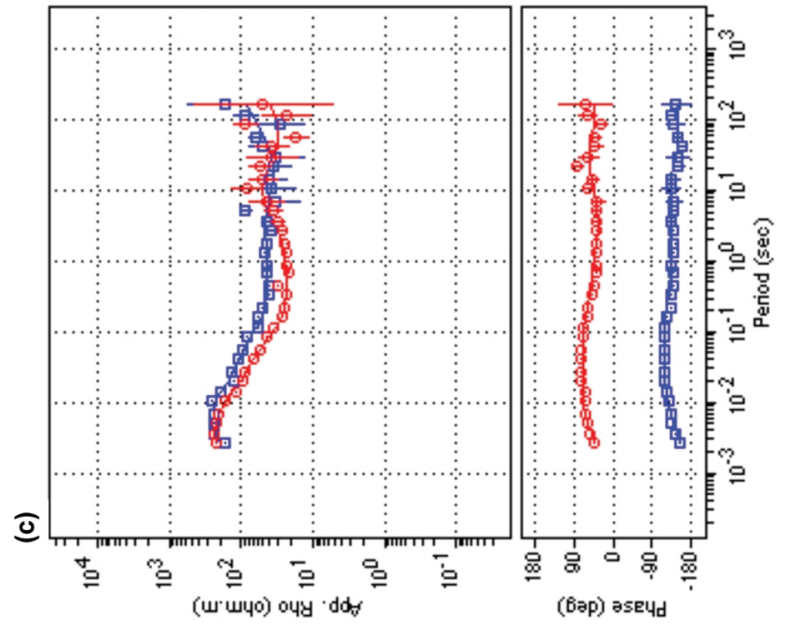

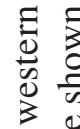

30

苋造

क

它尝

తิ

i.

雳

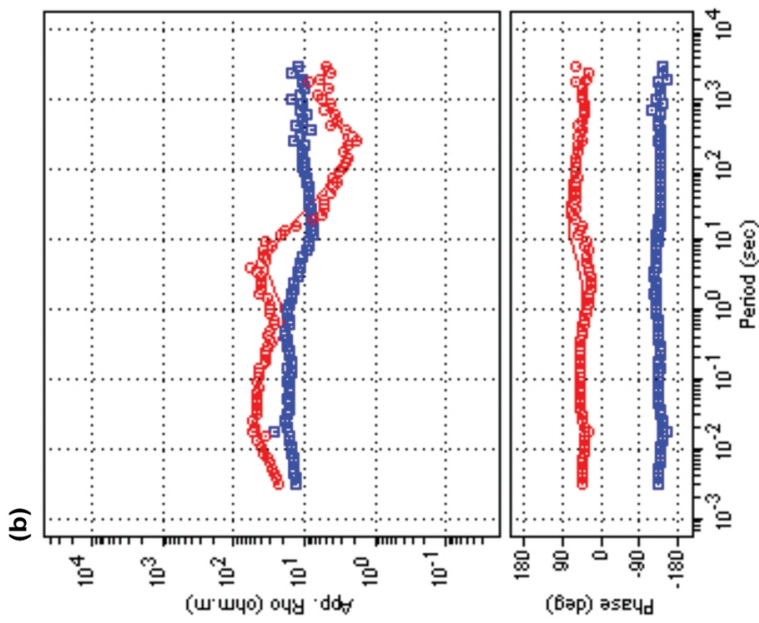

क ष

․․․

고엡

完的

总 $\frac{0}{0}$

包

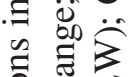

을

元

○苞方

送

递焉

曲:

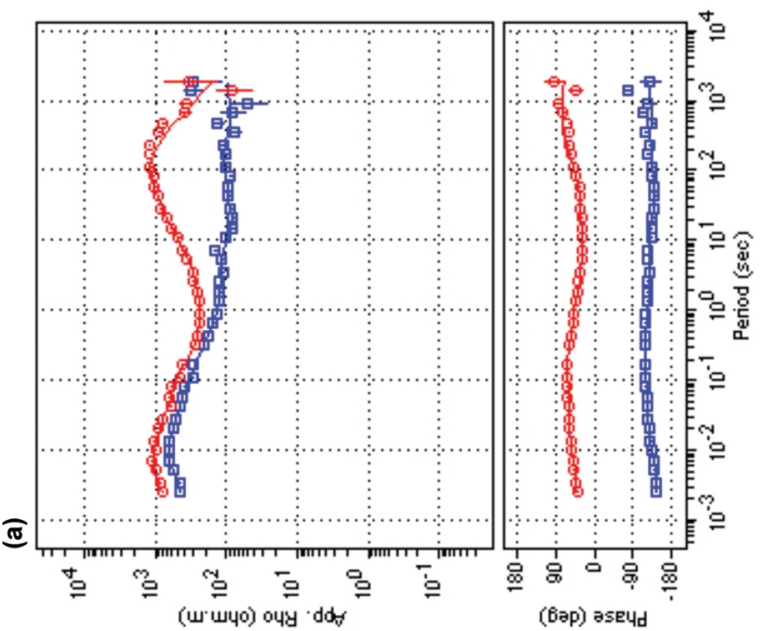

。ั

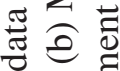

$\sum \stackrel{0}{0}$

ป

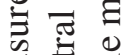

芯苛

i

$\dot{0}$ 


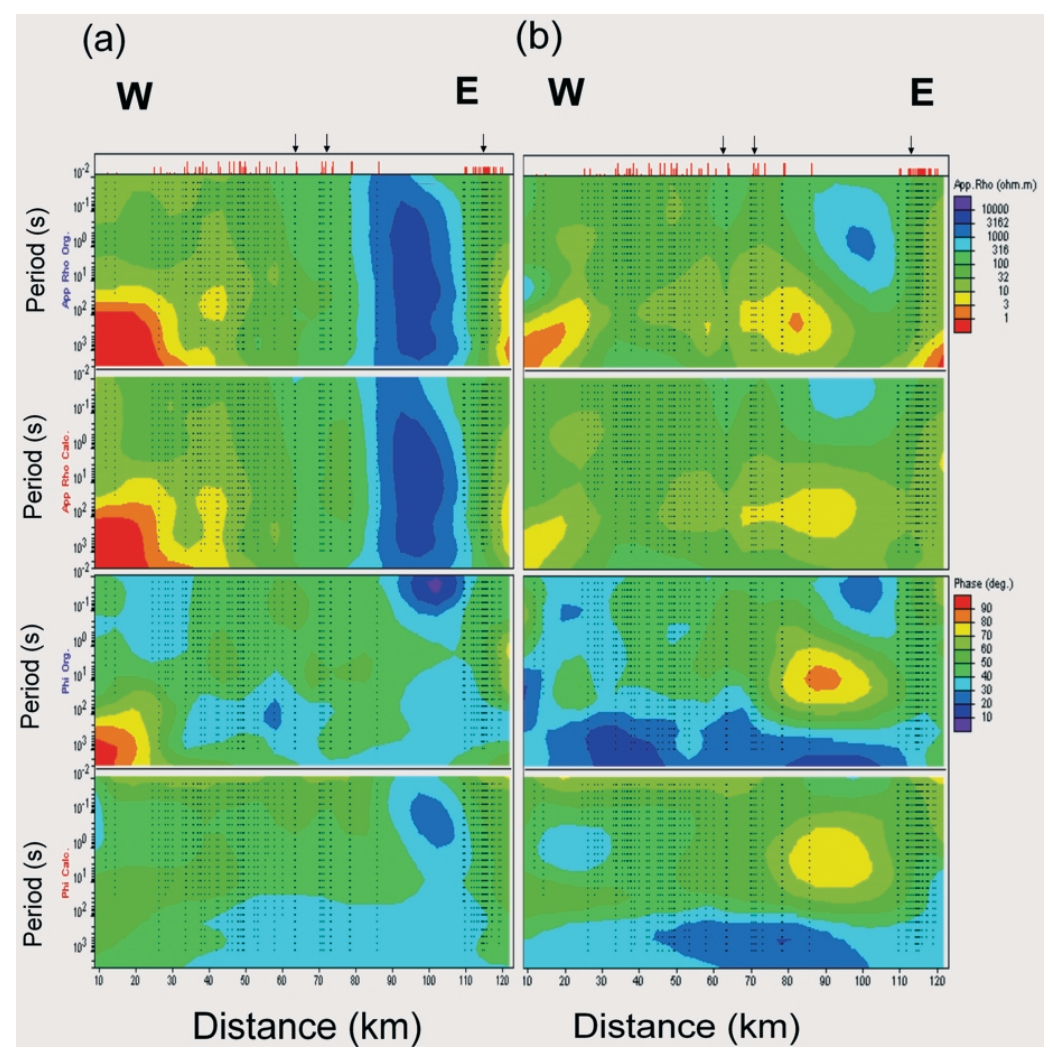

Fig. 3. A comparison between the observed and the calculated pseudo-sections of the joint TE/TM inversion of the WE profile: (a) TM mode (from top to bottom): Observed resistivity profile, calculated resistivity profile, observed phase profile and calculated phase profile. (b) TE mode (from top to bottom): Observed resistivity profile, calculated resistivity profile, observed phase profile and calculated phase profile. Dots in each profile are data points; three inverted arrows on top of each profile indicate the locations of MT data in Fig. 2.

resistive below a given depth. If the MT data cannot sense the bottom of the conductive layer, then the resistive region will not affect the data misfit. The depth of the top of the resistive half-space is moved upwards until the MT data can no longer be fit. This determines the shallowest conductor permitted by the data.

To invert the central Taiwan data, a high-resistivity $(1000 \mathrm{ohm}-\mathrm{m})$ half-space was added to the starting model at a depth of $50 \mathrm{~km}$. The resistivity model below this depth was fixed, and thus the inversion algorithm was forced to place all the conductive structure required by the 
MT data above this depth. This process was then repeated with a progressively shallower resistive basement. In each inversion, both the TE and TM mode data were fit. The inversions were performed with two geoelectric strike directions (1) NS and (2) $\mathrm{N} 20^{\circ} \mathrm{E}$. The inversion was allowed 50 inversion steps. An error floor of 3 per cent has been used for all phase data and 5 per cent for apparent resistivity data. Data errors smaller than this floor level are replaced with the error floor value. The models derived from these inversions for both geoelectric strike directions are shown in Fig. 4.

Based on the root-mean-square (rms) misfit for each model (Fig. 4), it can be seen that models with a strike direction $\mathrm{N} 20^{\circ} \mathrm{E}$ (Fig. $4 \mathrm{~b}, \mathrm{rms} 8.5$ on average) fit better than those with strike NS (Fig. 4a, rms 12.3 on average). In Fig. 4b, the resistive basement at $30 \mathrm{~km}$ depth (Fig. 4b-2) fits the measured data best $(\mathrm{rms}=8.52)$; as the basement is at $30 \mathrm{~km}$ depth, the misfit increases significantly (greater than 8.52). The non-uniqueness of the MT model can be clearly seen in Fig. 4. Despite differing strike directions and basement depths, they all exhibit two conductive anomalies, one beneath the Central Ranges and the other beneath the Western Foothills. The existence of a conductive middle crust is not dependent on the choice of electrical strike direction and resistive basement depth. It should also be noted that in all models, there exists a conductive anomaly beneath the Coastal Range.

The comparisons between the observed and the calculated pseudo-sections for the best fitting model (Fig. 4b-2) of the Central Taiwan profile are shown in Fig. 3. The overall fit between the observed and calculated apparent resistivity and phase of both modes were good.

\section{RESULTS AND DISCUSSIONS}

The preferred 2-D resistivity models are displayed in Fig. 5. The MT soundings (indicated on top of the profile) resolved the structure deeper than $25 \mathrm{~km}$ beneath central Taiwan. The seismicity from 1990 to 2000 that was recorded by the Central Weather Bureau Seismic Network is also shown.

The most significant feature in the resistivity models is the existence of two conductivity anomalies, $\mathrm{C} 1$ and $\mathrm{C} 2$; with resistivities lower than $30 \mathrm{ohm}-\mathrm{m}$. Conductor $\mathrm{C} 1$ is located at a depth of about $20 \mathrm{~km}$ below the Coastal Plains. C2 is located beneath the Central Ranges at $20 \mathrm{~km}$ depth, and extends discontinuously to the surface, at the contact of the HR and the CR. As mentioned before, the resistivity of the Earth is sensitive to the presence of small amounts of fluid; therefore, the possible cause of the $\mathrm{C} 1$ and $\mathrm{C} 2$ is some type of fluids.

To determine which type of fluids is causing the low resistivity is not simple. The characteristics of the low resistivity anomalies $\mathrm{C} 1$ and $\mathrm{C} 2$ are quite different. $\mathrm{C} 1$ is flat lying and extends horizontally east-west. In contrast conductor $\mathrm{C} 2$ is quite thin and extends vertically to the surface. Both $\mathrm{C} 1$ and $\mathrm{C} 2$ are regions of low seismic activity. Note that the seismicity scatters above $\mathrm{C} 1$, and that it is high near and extends to the edges of $\mathrm{C} 1$. This is consistent with model of Ague et al. (1998) who suggested that intraplate earthquake swarms are triggered by fluids which migrate into less permeable crust. Alternatively, the high seismicity might be due to local stress accumulation near the fluid reservoir. The conductors may imply fluids accommodated by the enhanced porosity due to local stress accumulation. Ogawa and 
(a) Strike NS
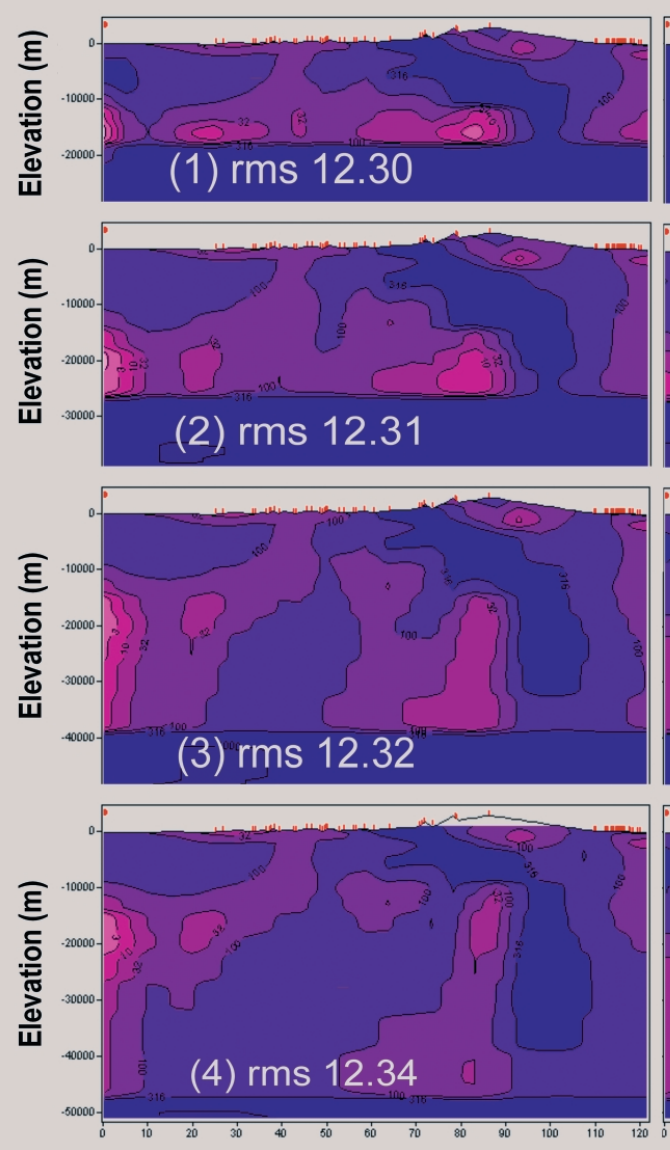

Distance (km) (b) Strike $\mathrm{N} 20^{\circ} \mathrm{E}$
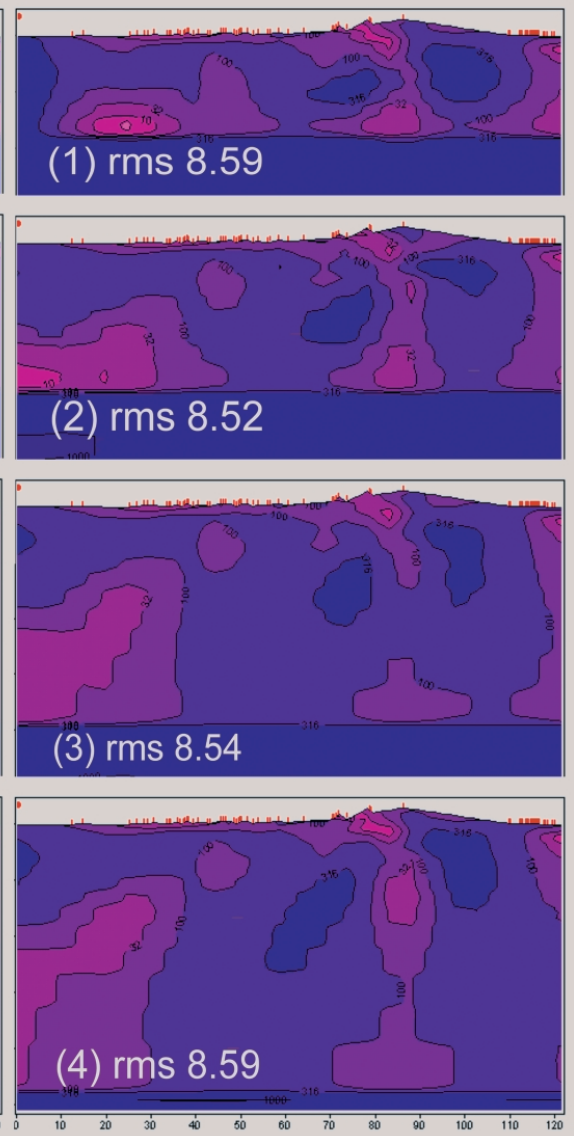

\section{Distance (km)}

ohm-m

Fig. 4. Resistivity models inverted from the WE line data by using the constrained inversion with a $1000 \mathrm{ohm}-\mathrm{m}$ basement fixed at elevations (1) $-20 \mathrm{~km}$, (2) $-30 \mathrm{~km}$, (3) $-40 \mathrm{~km}$, and (4) $-50 \mathrm{~km}$. (a) Models are inverted using the NS strike. (b) Models are inverted using the $\mathrm{N} 20^{\circ} \mathrm{E}$ strike (general geologic strike of Taiwan). Notice the increase in electrical conductivity (in red color) as the basement is moving up; when the resistive basement is at $30 \mathrm{~km}$ using the $\mathrm{N} 20^{\circ} \mathrm{E}$ strike, the model responses fit the measured data best as their overall rms show the lowest value 8.52. 


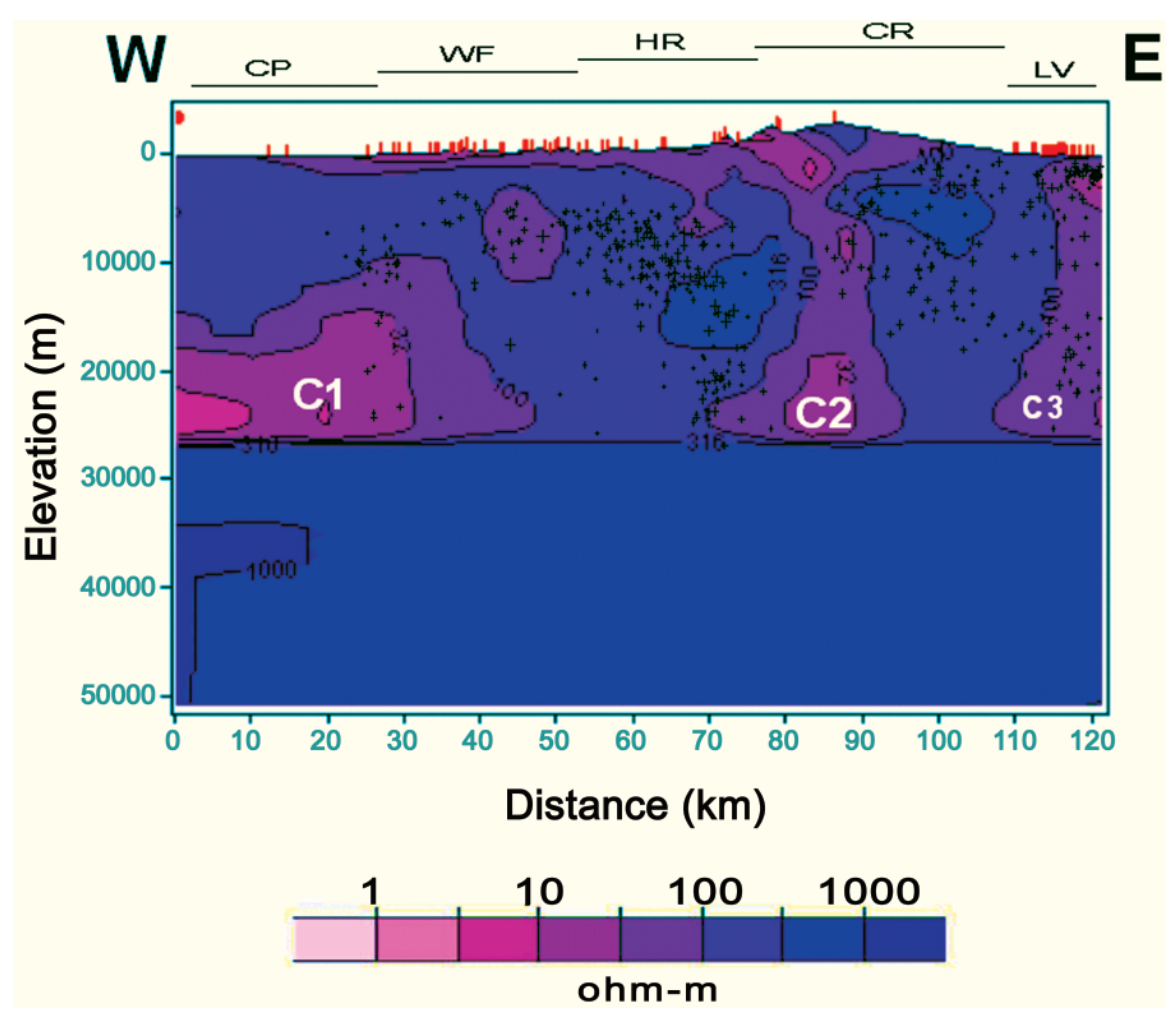

Fig. 5. Subsurface resistivity structures obtained from the constrained 2-D inversion of the joint TE/TM inversion of the WE-line in central Taiwan (same as in Fig. 4b-2); the most significant feature is the existence of low resistivity anomalies, $\mathrm{C} 1, \mathrm{C} 2$, and $\mathrm{C} 3$. The vertical bars (red) on the surface topography indicate the MT sounding points while the crosses (black) on the subsurface with proportional sizes indicate epicenters with magnitudes greater than 4.0 recorded by the Central Weather Bureau Seismic Network (CWBSN) from 1990 to 2000. The vertical scale is exaggerated for purpose of clarity. $\mathrm{CP}=$ Coastal Plain; $\mathrm{WF}=$ Western Foothills; $\mathrm{HR}=$ Hsuehshan Range; $\mathrm{CR}=$ Central Range; $\mathrm{LV}=$ Longitudinal Valley.

Honkura (2004) found mid-crustal conductors in central Japan. The depths of the tops of these features correlate well with the depth at which seismicity is cut off. The seismicity is localized in clusters in the resistive crust where a mid-crustal conductors is located below. This implies that the local distribution of fluids below the brittle-ductile boundary may control the location of earthquakes in the overlying crust, as the fluids migrate into the resistive zone and trigger earthquakes. 
Conductor $\mathrm{C} 2$ is located beneath the highest part of the Central Range, where high-grade metamorphic rocks outcrop. The seismicity scatters above $\mathrm{C} 2$ and an aseismic zone is distributed around C2. Relatively high heat flow values $\left(\sim 200 \mathrm{~mW} \mathrm{~m}^{-2}\right)$ are observed beneath the Central Range (Lin 2000). However, thermal modeling predicts a temperature of $400^{\circ} \mathrm{C}$ at $20 \mathrm{~km}$ depth beneath the Central Range (Lin 2000). This temperature is insufficient to produce such a low resistivity anomaly without the presence of aqueous fluids (Chen and Chen 2002). These fluids could be produced by the dehydration of the subducting plate. This has previously been suggested as an explanation for the common occurrence of low resistivities in the continental crust (Jones 1987; Hyndman et al. 1993). The feature C2 is also very similar to that imaged beneath the South Island of New Zealand by Wannamaker et al. (2002). In this context crustal thickening generates fluids that produce a low resistivity in the crustal root.

Another zone of low resistivity (C3) was also detected beneath the Longitudinal Valley although its resistivity is not as low as the $\mathrm{C} 1$ or $\mathrm{C} 2$. The location of the low resistivities in the Longitudinal Valley agree well with the known suture trace on the surface between the Philippine Sea and the Eurasian plates. Based on the MT data, this suture trace extends from the surface to the depth of more than $30 \mathrm{~km}$.

The MT data thus give evidence for the widespread distribution of crustal fluids beneath central Taiwan. These low resistivity zones show the regions where fluids are being generated and transported to the surface. Since fluids can weaken the crust, they may represent zones of concentrated deformation in the active Taiwan orogen.

\section{CONCLUSIONS}

The most significant feature of the MT derived resistivity model is the existence of three low resistivity anomalies in the mid-crust. The spatial correlation between the Coastal Plains low resistivity anomaly $(\mathrm{C} 1)$ and the occurrence of the high seismicity cluster suggests that fractured rocks with deep crustal fluids enhance the interconnectivity of pore spaces and reduce the resistivity in the low resistivity anomaly. On the contrary, the aseismic zone around $\mathrm{C} 2$ in the Central Ranges coincides with the observed high heat flow in this region. The low resistivity is produced by a combination of crustal fluids and the enhanced temperature. Conductor C3 in the Longitudinal Valley coincides with the mapped trace of the suture between the Philippine Sea and Eurasian plates. If these regions of high conductivity are the result of zones of well-connected, high porosity fluids then they might also represent zones of active crustal deformation. The GPS observations of the abrupt changes in horizontal velocity associated with the Coastal Plains and Longitudinal Valley support this hypothesis (Yu et al. 1990).

The central Taiwan MT profile shows that electrical resistivity contains important information about the tectonics of Taiwan. Additional MT data are required to determine how the structure varies along strike. Understanding this structure in 3-D will require collection of high quality broadband MT data in both southern and northern Taiwan.

Acknowledgements This project was funded by the National Science Council of the Republic of China under grants NSC91-2111-M008-015, NSC92-2111-M008-015 and NSC93-2119M008-005. The field data were acquired by the crew of MT research group of National Central 
University (NCU), National Chung Cheng University (CCU) and the University of Alberta. We would like to thank two reviews, Dr. Lun-Tao Tong and the anonymous, for their constructive and thoughtful comments. We also acknowledge landlords for permissions. Seismicity data were generously supplied by the Central Weather Bureau Seismic Network (CWBSN), Taiwan.

\section{REFERENCES}

Ague, J., J. Park, and D. M. Rye, 1998: Regional metamorphic dehydration and seismic hazard. Geophys. Res. Lett., 25, 4221-4224.

Chen, C. C., and C. S. Chen, 1998: Preliminary result of magnetotelluric soundings in the fold-thrust belt of Taiwan and possible detection of dehydration. Tectonophysics, 292, 101-117.

Chen, C. C., and C. S. Chen, 2000: Preliminary report on the Sanyi-Puli seismic zone conductivity anomaly and its correlation with velocity structure and seismicity in the Northwestern Taiwan. Earth Planets Space, 52, 377-381.

Chen, C. C., and C. S. Chen, 2002: Sanyi-Puli conductivity anomaly in NW Taiwan and its implication for the tectonics of the 1999 Chi-Chi earthquake. Geophys. Res. Lett., 29, Art. No. 1166, doi: 10.1029/2001GL013890.

Chen, C. C., C. S. Chen, and C. F. Shieh, 2002: Crustal electrical conductors, crustal fluids and 1999 Chi-Chi, Taiwan, earthquake. Terr. Atmos. Ocean. Sci., 13, 367-374.

Gamble, T. D., W. M. Goubau., and J. Clarke, 1979: Magnetotellurics with a remote reference. Geophysics, 44, 53-68.

Ho, C. S., 1988: An introduction to the geology of Taiwan, explanatory text of the geological map of Taiwan, $2^{\text {nd }}$ Ed., Ministry of Economic Affairs, Taipei, Taiwan, 192 pp.

Hyndman, R. D., L. L. Vanyan, G. Marquis, and L. K. Law, 1993: The origin of electrically conductive lower crustal continental crust: saline water or graphite? Phys. Earth Planet. Inter., 81, 325-344.

Jones, A. G., 1987: MT and reflection: an essential combination. Geophys. J. R. Astron. Soc., 89, 7-18.

Li, S., M. J. Unsworth, J. R. Booker, W. Wei, H. Tan, and A. G. Jones, 2003: Partial melt or aqueous fluid in the mid-crust of Southern Tibet? Constraints from INDEPTH magnetotelluric data. Geophys. J. Int., 153, 289-304.

Lin, C. H., 2000: Thermal modeling of continental subduction and exhumation constrained by heat flow and seismicity in Taiwan. Tectonophics, 324, 189-201.

Mitsuhata, Y., Y. Ogawa, M. Mishina, T. Kono, T. Yokokura, and T. Uchida, 2001: Electromagnetic heterogeneity of the seismogenic region of 1962 M6.5 Northern Miyagi Earthquake, northeastern Japan. Geophys. Res. Lett., 28, 4371-4374.

Ogawa, Y., M. Mishima, T. Goto, H. Satoh, N. Oshiman, T. Kasaya, Y. Takahashi, T. Nishitani, S. Y. Sakanaka, M. Uyeshima, Y. Takahashi, Y. Honkura, and M. Matsushima, 2001: Magnetotelluric imaging of fluids in intraplate earthquake zones, NE Japan back arc. Geophys. Res. Lett., 28, 3741-3744. 
Ogawa, Y., and Y. Honkura, 2004: Mid-crustal electrical conductors and their correlations to seismicity and deformation at Itoigawa-Shizuoka Tectonic Line, Central Japan. Earth Planets Space, 56, 1285-1291.

Rau, R. J., and F. T. Wu, 1995: Tomographic imaging of lithospheric structures under Taiwan. Earth Planet. Sci. Lett., 133, 517-532.

Rodi, W., and R. L. Mackie, 2001: Nonlinear conjugate gradients algorithm for 2-D magnetotelluric inversion. Geophysics, 66, 174-187.

Teng, L. S., 1990: Geotectonic evolution of late Cenozoic arc-continental collision in Taiwan. Tectonophysics, 183, 57-76.

Unsworth, M. J., A. G. Jones, W. Wei, G. Marquis, S. Gokarn, and J. Spratt, 2005: Crustal rheology of the Himalaya and Southern Tibet inferred from magnetotelluric data. Nature, 438, 78-81, doi:10.1038/nature04154.

Wannamaker, P. E., G. R. Jiracek, J. A. Stodt, T. G. Caldwell, V. Gonzalez, J. McKnight, A. D. Porter, 2002: Fluid generation and pathways beneath an active compressional orogen, the New Zealand Southern Alps, inferred from magnetotelluric data. J. Geophys. Res., 107, 2117, doi: 10.1029/2001JB000186.

Wu, F. T., R. J. Rau, and D. Salzberg, 1997: Taiwan orogeny: thin-skinned or lithospheric collision? Tectonophysics, 274, 191-220.

Yu, S. B., D. D. Jackson, G. K. Yu, and C. C. Liu, 1990: Dislocation model for crustal deformation in the Longitudinal Valley area, eastern Taiwan. Tectonophysics, 183, 97-109.

Chen, C. S., C. C. Chen, C. W. Chiang, H. L. Shu, W. H. Chiu, M. J. Unsworth, and E. Bertrand, 2007: Crustal resistivity anomalies beneath central Taiwan imaged by a broadband magnetotelluric transect. Terr. Atmos. Ocean. Sci., 18, 19-30. 